\title{
Cutaneous Follicular Lymphoma
}

National Cancer Institute

\section{Source}

National Cancer Institute. Cutaneous Follicular Lymphoma. NCI Thesaurus. Code C7218.

A follicular lymphoma involving the skin. A cutaneous follicular lymphoma may be metastatic to the skin from the lymph nodes or other anatomic sites or primary (cutaneous follicle center lymphoma). --2003 